\title{
Low-Temperature-Curing Type \\ Positive-Tone Photosensitive Polyimide Coatings for Insulating Layer in OLED Displays
}

\section{RYOJI OKUDA, KAZUTO MIYOSHI, NANA ARAI, MASAO TOMIKAWA, and GENTARO OHBAYASHI}

\author{
Electronic and Imaging Materials Research Laboratories, \\ Toray Industries, Inc. \\ 1-2, Sonoyama 3-chome, Otsu, Shiga 520-0842, Japan
}

Keywords: low temperature curing, photosensitive polyimide, OLED, insulating layer

\section{Introduction}

Organic light emitting diode (OLED) displays are promised to be one of the next generation displays due to their various advantages including a wide viewing angle, fast response, low power, and simple structure. OLED displays are composed of an ITO glass, an insulating layer, emitting layers, an upper electrode, and a drive unit basically (Figure 1) ${ }^{1}$. The insulating layer is patterned by photolithographic technology. Low curing temperature is desirable because of its influence on electrical properties. Requirements for the insulating layer are shown as followings.

1) Photosensitivity

2) To be curable at less than $250 \mathrm{C}$

3) Round shape and 10-20 degree tapered-angle at the cross section

4) High and stable dielectric strength

5) Thermal stability

6) Chemical stability

Positive-tone photosensitive polyimide meets all requirements except for the curing temperature. In order to meet the requirement of lower temperature curing, we developed novel low-temperature-curing type positive-tone photosensitive polyimide coatings. In this article, we introduce the new photosensitive polyimide coatings from the point of theirs properties for the OLED insulating layer.

\section{Features}

The new positive-tone photosensitive polyimide coatings are composed of a polyimide precursor, photoactive compounds, and solvents.

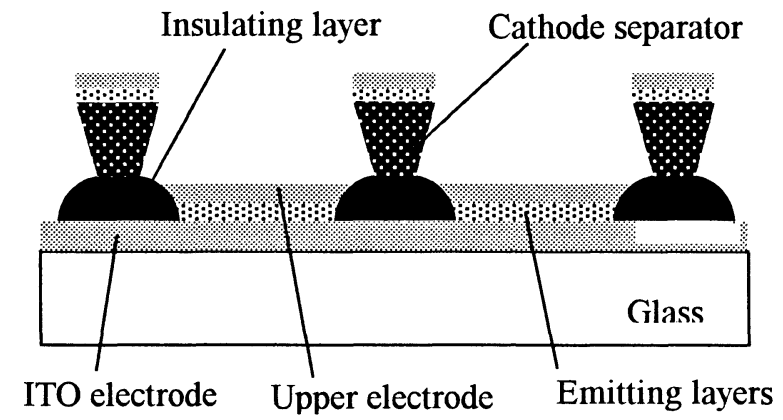

Figure 1. An example for OLED structure

Careful choosing a structure of the polyimide precursor and photoactive compounds, the coatings have following features.

- A TMAH aqueous solution (2.38 wt\%) developability

- Low temperature curing

- Round shape and 10-20 degree tapered-angle at the cross section

- High and stable dielectric strength

- Excellent thermal stability

- Good adhesion to various substrates

- Good UV-O $\mathrm{O}_{3} / \mathrm{O}_{2}$-plasma resistance

- Good solution stability

\section{Patterning properties}

A patterning process example for $1 \mu \mathrm{m}$ film thickness after curing is shown in the Table 1. The patterning method includes spin coating, prebaking, exposure, development and curing. The process is similar to a conventional positive 
photo-resist patterning process. The new coatings can be used with a LCD patterning system, which is composed of a coater, an aligner (exposure tool), and a developer.

Table 1. A patterning process example for $1 \mu \mathrm{m}$ after curing

\begin{tabular}{|c|c|c|}
\hline Procedure & Condition & $\begin{array}{l}\text { Thickness } \\
(\mu \mathrm{m})\end{array}$ \\
\hline Spin coating & $1200 \mathrm{rpm}$ for $30 \mathrm{sec}$ & - \\
\hline Prebaking & $\begin{array}{l}120 \mathrm{C} \text { for } 120 \mathrm{sec} \\
\text { (Hot plate) }\end{array}$ & 1.52 \\
\hline Exposure & $\begin{array}{c}54 \mathrm{~mJ} / \mathrm{cm}^{2} \\
\text { (Broad band; at i-line) }\end{array}$ & - \\
\hline Development & 20s (Dipping) & 1.39 \\
\hline \multirow[b]{2}{*}{ Curing } & $230 \mathrm{C}$ for $30 \mathrm{~min}$ (Oven) & \multirow[b]{2}{*}{1.01} \\
\hline & $\begin{array}{l}230 \mathrm{C} \text { for } 10-20 \mathrm{~min} \\
\text { (Hot plate) }\end{array}$ & \\
\hline
\end{tabular}

\section{Low temperature curing}

Conventional polyimide coatings need high temperature $(>300 \mathrm{C})$ curing. In the OLED manufacturing, lower curing temperature than $250 \mathrm{C}$ is preferable due to an influence on work function of ITO. Careful choosing a structure of the polymide precursor, the new coatings can be cured at lower temperature than $250 \mathrm{C}$. The coatings cured at $230 \mathrm{C}$ have sufficient properties for the insulating layer as followings.

\section{Cross Sectional View}

Photo 1 shows cross sectional views of $5 \mu \mathrm{m}$ and $10 \mu \mathrm{m} L \& S$ for $1 \mu \mathrm{m}$ thickness after curing. The obtained patterns are enough fine for the insulating layer.

A shape at the pattern edge of the insulating layer is important for OLED displays. The rectangle shape causes electrical problems (electrical short, electric breakdown, and leakage current, etc.), because the cured film thickness of the insulating layer is thinner at the edge part than at the flat part. The round shape is suitable for the OLED insulating layer. Photo 1 represents the pattern edge from the new coatings. It shows a round shape and looks suitable for the insulating layer. The lower tapered angle at the pattern edge, 10-20 degree, is also proper for the insulating layer. We can control the edge from 10 degree to 70 degree by changing the fomulation.

\section{Dielectric strength stability}

The insulating layer requires the high and stable insulation performance. The performance is exampled by dielectric strength. Figure 2 shows thermal stability of dielectric strength for the new

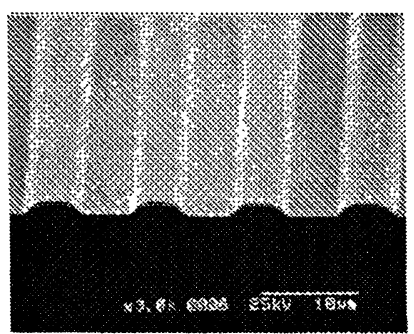

(a) $5 \mu \mathrm{m} L \& \mathrm{~S}$

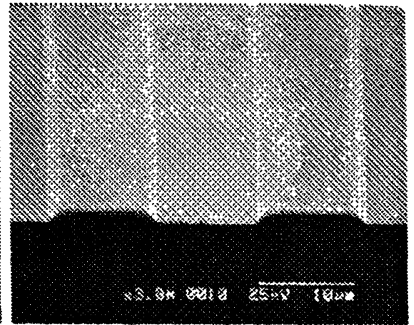

(b) $10 \mu \mathrm{m} \mathrm{L \& S}$
Photo 1. Cross sectional views for $1 \mu \mathrm{m}$ thickness after curing (230C for $30 \mathrm{~min}$ ); (a) $5 \mu \mathrm{m} \mathrm{L \& S}$, (b) $10 \mu \mathrm{m}$ L\&S

Exposure: $54 \mathrm{~mJ} / \mathrm{cm}^{2}$ (Broad band, at I-line)

Development: 20s (2.38\% TMAH, dipping)

Curing: $230 \mathrm{C}$ for $30 \mathrm{~min}$ in oven

coatings after curing with a comparison of conventional positive photo-resist "OFPR-800" (Tokyo-Ohka). Figure 3 shows light stability of them after curing. The new coatings have high dielectric strength about $500 \mathrm{~V} / \mathrm{mm}$ and $10 \%$ loss in 15 hours at $85 \mathrm{C}$, while the conventional photo-resist has $300 \mathrm{~V} / \mathrm{mm}$ and $90 \%$ loss (Figure 2). In addition, the new coatings have no loss in 15 hours irradiation, while the conventional photo-resist has $50 \%$ loss in 15 hours (Figure 3). These figures prove that the new coatings have high electrical reliability on daily use.

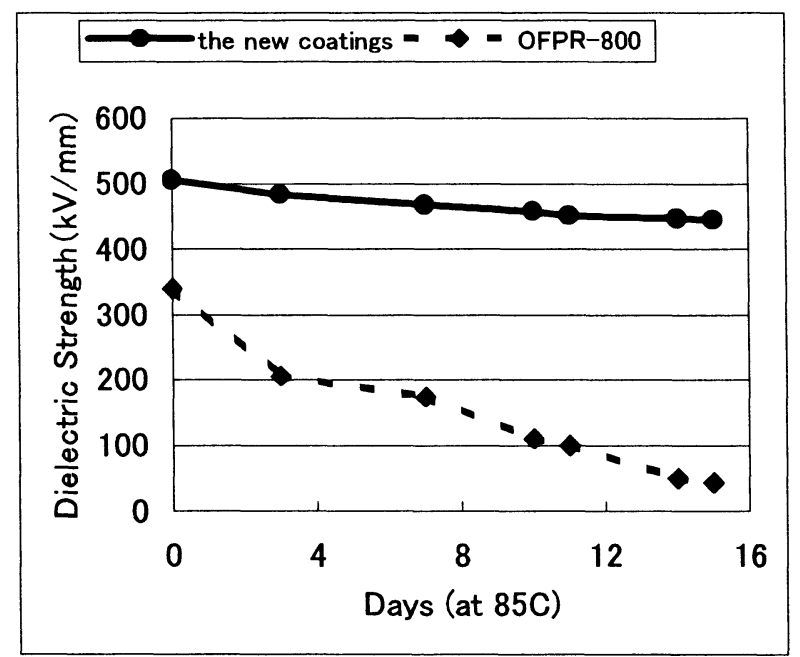

Figure 2. Thermal stability of dielectric strength after curing

Curing: $230 \mathrm{C}$ for $30 \mathrm{~min}$ (the new coatings)

$150 \mathrm{C}$ for $30 \mathrm{~min}$ (OFPR-800)

Storage Temperature: $85 \mathrm{C}$

Dielectric strength measurement: JIS C 2110 


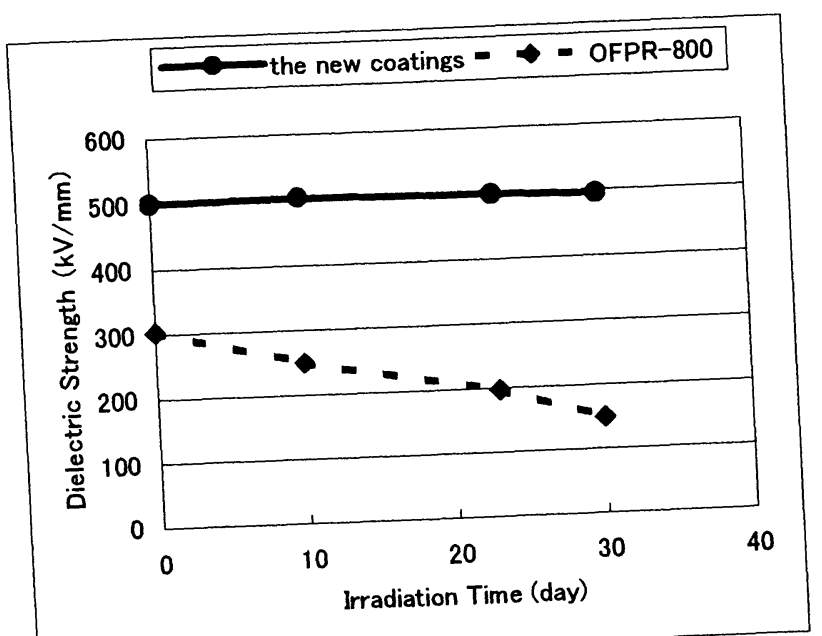

Figure 3. Light stability of dielectric strength after curing

Curing: $230 \mathrm{C}$ for $30 \mathrm{~min}$ (the new coatings) 150C for $30 \mathrm{~min}$ (OFPR-800)

Irradiation: Xe longlife Fademeter (Suga) Irradiance(300-400nm) $37 \mathrm{~mW} / \mathrm{m}^{2}$ Illuminance $(400-700 \mathrm{~mm}) 7300 \mathrm{Lx}$

Dielectric strength measurement: JIS C 2110

\section{Outgas}

The insulating layer requires no outgas due to contact directly with OLED emitting materials in a pixel. Outgas is thought to be one of the reasons for "pixel shrinkage", which is one of the serious problems for OLED displays, and consequently lower outgas is desirable. Outgas can be estimated at weight loss by TGA analysis. Figure 4 shows normalized weigh loss of the cured film in maintained at $120 \mathrm{C}$ with a comparison of conventional photo-resist "OFPR-800". On one hand the new coatings show no weight loss in 24 hours; on the other hand, conventional photo-resist shows $15 \%$ weight loss in 24 hours.

TG-MS analysis can determine a trace of volatile components. Figure 5 represents volatile components from the cured film in maintained at $120 \mathrm{C}$. No volatile component was detected in the identification limit.

These mean that the new coatings have high thermal stability and no influence on OLED emitting materials.

\section{Adhesive properties}

Adhesion of the cured film to various substrates was determined by a Scotch tape ${ }^{\circledR}$ delamination method (JIS K 5400) with PCT treatment. PCT (pressure cooker test) means a kind of accelerated test whose condition is $121 \mathrm{C}$, $2.0 \times 10^{5} \mathrm{~Pa}(2.0 \mathrm{~atm})$, and $100 \% \mathrm{RH}$. Table 2 shows the test result of glass, ITO, $\mathrm{SiO} 2$, and $\mathrm{Cr}$ substrates.

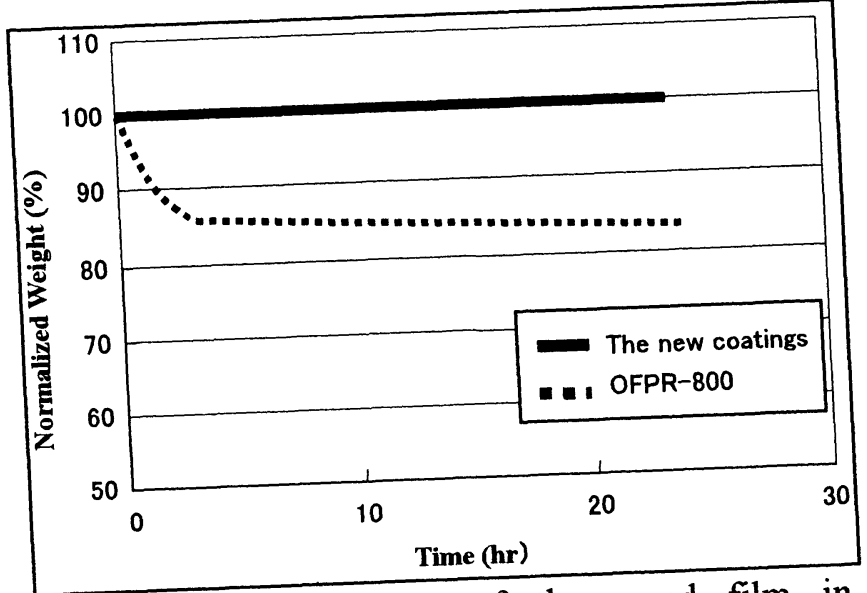

Figure 4. Weight loss of the cured film in maintained at $120 \mathrm{C}$

Curing: $230 \mathrm{C}$ for $30 \mathrm{~min}$ (the new coatings)

$150 \mathrm{C}$ for $30 \mathrm{~min}$ (OFPR-800)

TGA apparatus: TGA-50 (Shimazu)

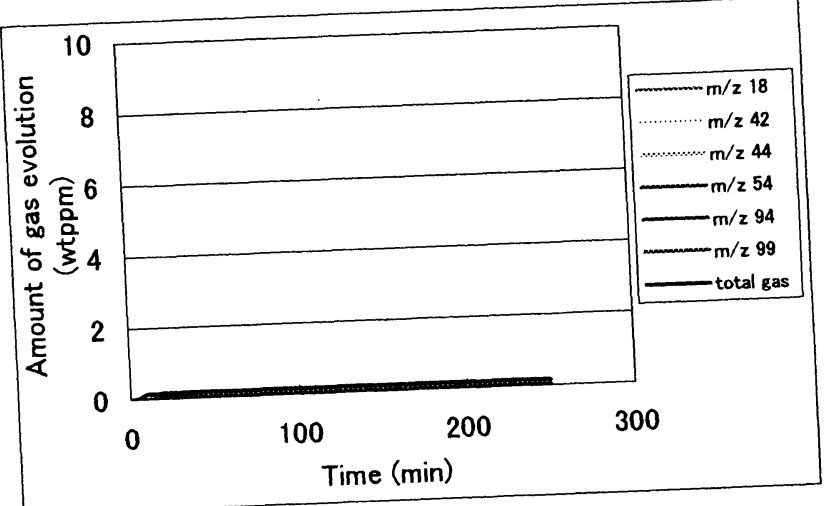

Figure 5. Volatile components from the cured film of the new coatings in maintained at $120 \mathrm{C}$

Curing: $230 \mathrm{C}$ for $30 \mathrm{~min}$

TG-MS apparatus: GC/MS QP5050A (Shimazu)

The new coatings show good adhesion to various substrates before and after PCT treatment in 400 hours. This result means that the new coatings have good adhesion to apply to OLED displays.

Table 2. Adhesion to various substrates after curing

\begin{tabular}{|c|c|c|c|c|c|}
\hline \multirow{2}{*}{ Substrate } & \multicolumn{5}{|c|}{ PCT* treatment time (hr) } \\
\cline { 2 - 6 } & 0 & 50 & 100 & 200 & 400 \\
\hline Glass & $0 / 10^{* *}$ & $0 / 10$ & $0 / 10$ & $0 / 10$ & $0 / 10$ \\
\hline ITO & $0 / 10$ & $0 / 10$ & $0 / 10$ & $0 / 10$ & $0 / 10$ \\
\hline $\mathrm{SiO} 2$ & $0 / 10$ & $0 / 10$ & $0 / 10$ & $0 / 10$ & $0 / 10$ \\
\hline $\mathrm{Cr}$ & $0 / 10$ & $0 / 10$ & $0 / 10$ & $0 / 10$ & $0 / 10$ \\
\hline
\end{tabular}

Curing: $230 \mathrm{C}$ for $30 \mathrm{~min}$

*PCT condition: $121 \mathrm{C}, 2.0 \times 10^{5} \mathrm{~Pa}$ (2.0atm), and $100 \% \mathrm{RH}$

**Delamination ratio; the number of delaminated parts / the number of all test parts. " $0 / 10$ " means no delamination. 


\section{9. $\mathrm{UV}-\mathrm{O}_{3} / \mathrm{O}_{2}$-plasama Resistance}

$\mathrm{UV}^{-\mathrm{O}_{3}} / \mathrm{O}_{2}$-plasama resistance of an insulating layer is important for some cleaning processes before vacuum evaporation process of emitting materials. The insulating layer is affected by UV-O $\mathrm{O}_{3} / \mathrm{O}_{2}$-plasama cleaning, which is used for removing contaminations on a pixel.

Figure 6 and 7 represent $\mathrm{UV}-\mathrm{O}_{3}$ and $\mathrm{O}_{2}$-plasama resistance of the cured film respectively, with a comparison of conventional photo-resist "OFPR-800". These test conditions are listed below the figures respectively. With $\mathrm{UV}-\mathrm{O}_{3}$ treatment in $60 \mathrm{~min}$, the thickness reducing rate for the new coatings is a third of that for the photo-resist (Figure 6). With $\mathrm{O}_{2}$-plasma treatment in $20 \mathrm{~min}$, the thickness reducing rate for the new coatings is half of that for the photo-resist (Figure 7). These mean that $\mathrm{UV}-\mathrm{O}_{3}$ resistance and $\mathrm{O}_{2}$-plasama resistance of the new coatings are stronger than that of conventional photo-resist.

\section{Solution stability}

Solution stability of the coating is important for mass production process. Solution viscosity has an influence on coating thickness. Viscosity change of the new coatings at room temperature $(23 \mathrm{C})$ is exhibited in Figure 8 . The viscosity change is quite small. Even after a month, the viscosity change is less than $10 \%$ and film thickness change is negligible.

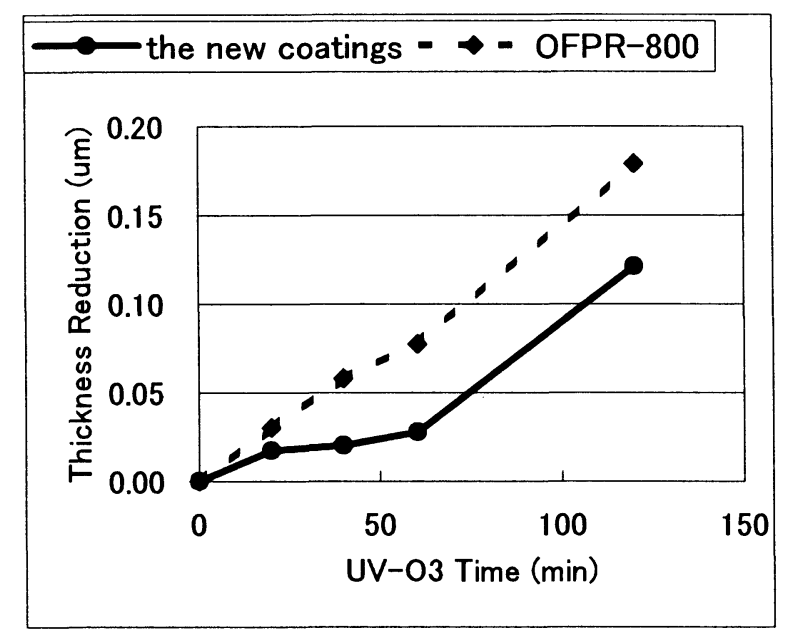

Figure 6. $\mathrm{UV}-\mathrm{O}_{3}$ resistance of the cured film

Curing: $230 \mathrm{C}$ for $30 \mathrm{~min}$ (the new coatings)

150C for 30min (OFPR-800)

UV- $\mathrm{O}_{3}$ apparatus: OC-4010 (Iwata Electronic)

$\mathrm{O}_{3}$ concentration: $100 \mathrm{ppm}$

Gap to lamp: $25 \mathrm{~mm}$

Illuminance $15 \mathrm{~mW} / \mathrm{cm}^{2}$ (at $254 \mathrm{~nm}$ )

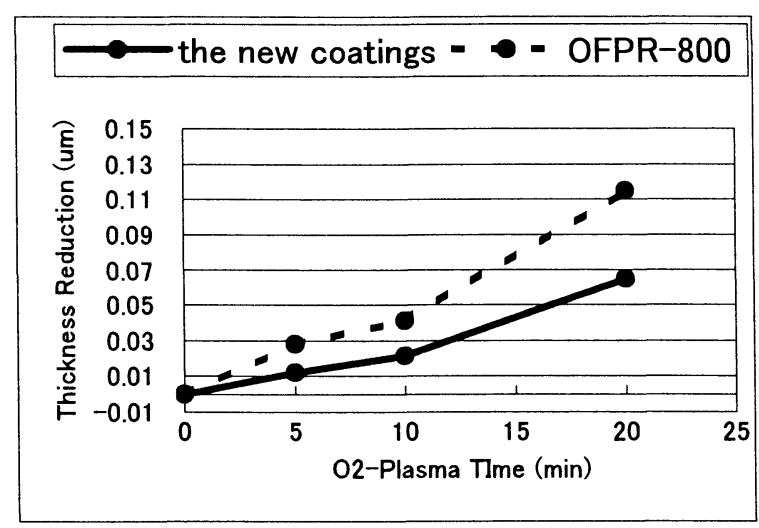

Figure 7. $\mathrm{O}_{2}$-plasma resistance of the cured film

Curing: $230 \mathrm{C}$ for $30 \mathrm{~min}$ (the new coatings)

$150 \mathrm{C}$ for $30 \mathrm{~min}$ (OFPR-800)

$\mathrm{O}_{2}$-plasma apparatus: PR-501A (YAMATO)

Power 300W

Degree of vacuum: $<1$ Torr

SWR: $<1.5 \%$

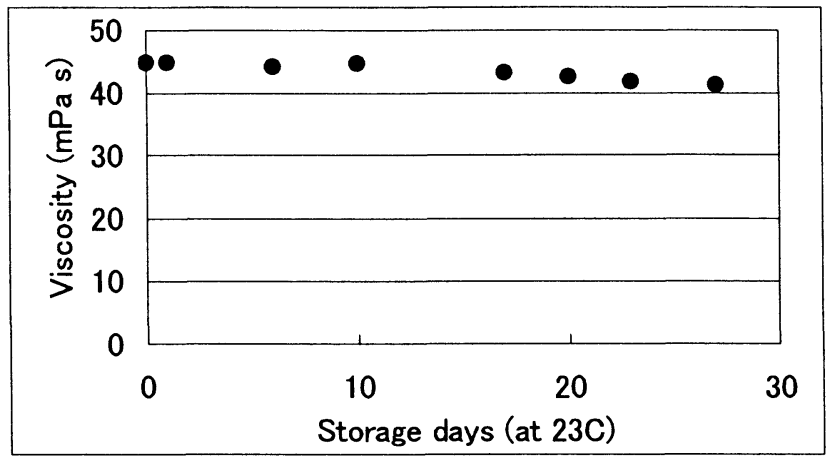

Figure 8. Viscosity change of the new coatings at room temperature

\section{Summary}

We developed the novel low-temperature-curing type positive-tone photosensitive polyimide coatings. The coatings have high reliability as well as good photolithographic performance with unique lower temperature curing nature. The coatings have high and stable electrical properties, excellent thermal stability (no outgas), good $\mathrm{UV}^{-} \mathrm{O}_{3} / \mathrm{O}_{2}$-plasma resistance, and good solution stability. These features promise that the new coatings are much suitable for the insulating layer in OLED displays.

\section{Reference}

1) H.Nakada and T.Thoma, Inorganic and Organic Electroluminescence, EL96, Berlin, 385(1996) 